\title{
Water-dielectric-breakdown relation for the design of large-area multimegavolt pulsed-power systems
}

\author{
W. A. Stygar, ${ }^{1}$ T. C. Wagoner, ${ }^{2}$ H. C. Ives,${ }^{3}$ Z. R. Wallace, ${ }^{2}$ V. Anaya, ${ }^{2}$ J. P. Corley, ${ }^{2}$ M. E. Cuneo, ${ }^{1}$ H. C. Harjes, ${ }^{1}$ \\ J. A. Lott, ${ }^{2}$ G. R. Mowrer, ${ }^{1}$ E. A. Puetz, ${ }^{1}$ T. A. Thompson, ${ }^{2}$ S. E. Tripp, ${ }^{2}$ J. P. VanDevender, ${ }^{1}$ and J. R. Woodworth ${ }^{1}$ \\ ${ }^{1}$ Sandia National Laboratories, Albuquerque, New Mexico 87185, USA \\ ${ }^{2}$ Ktech Corporation, Albuquerque, New Mexico 87123, USA \\ ${ }^{3}$ EG\&G, Albuquerque, New Mexico 87107, USA \\ (Received 24 March 2006; published 26 July 2006)
}

\begin{abstract}
We have developed an empirical electrical-breakdown relation that can be used to design large-area water-insulated pulsed-power systems. Such systems often form an integral part of multiterawatt pulsedpower accelerators, and may be incorporated in future petawatt-class machines. We find that complete dielectric failure is likely to occur in water between a significantly field-enhanced anode and a lessenhanced cathode when $E_{p} \tau_{\text {eff }}^{0.330 \pm 0.026}=0.135 \pm 0.009$. In this expression $E_{p} \equiv V_{p} / d$ is the peak value in time of the spatially averaged electric field between the anode and cathode (in $\mathrm{MV} / \mathrm{cm}$ ), $V_{p}$ is the peak voltage across the electrodes, $d$ is the distance between the anode and cathode, and $\tau_{\text {eff }}$ is the temporal width (in $\mu \mathrm{s}$ ) of the voltage pulse at $63 \%$ of peak. This relation is based on 25 measurements for which $1 \leq V_{p} \leq 4.10 \mathrm{MV}, 1.25 \leq d \leq 22 \mathrm{~cm}$, and $0.011 \leq \tau_{\text {eff }} \leq 0.6 \mu \mathrm{s}$. The normalized standard deviation of the differences between these measurements and the associated predictions of the relation is $12 \%$.
\end{abstract}

DOI: 10.1103/PhysRevSTAB.9.070401

PACS numbers: 52.80.Wq, 77.22.Jp, 84.60.Ve, 84.70.+p

\section{INTRODUCTION}

Pulsed-power accelerators, such as the 55-TW Z accelerator at Sandia National Laboratories [1-10], often include one or more electrical components that use water as an insulating medium. Several applications (e.g., inertial confinement fusion, high-energy-density-physics studies, and equation-of-state research) have motivated the community to develop conceptual accelerator designs that could produce electrical powers as high as $1000 \mathrm{TW}$ [11-23]; most of these designs also include waterinsulated components. Optimizing the calculated performance of such components for both terawatt- and petawattclass accelerators requires an estimate of the conditions under which the components are likely to suffer dielectric failure.

A number of useful water-dielectric-breakdown relations have been presented in the literature [24-33]. The relation developed by Eilbert and Lupton [26], which presently appears to be the most commonly used for the design of water-insulated systems, suggests that the probability of water breakdown in a uniform-electric-field system is $\sim 50 \%$ when

$$
E_{p} \tau_{\text {eff }}^{1 / 3} A^{0.058}=0.230 .
$$

The quantity $E_{p} \equiv V_{p} / d$ is the peak value in time of the spatially averaged electric field between the anode and cathode (in $\mathrm{MV} / \mathrm{cm}$ ), $V_{p}$ is the peak voltage across the electrodes, $d$ is the distance between the anode and cathode, $\tau_{\text {eff }}$ is the temporal width (in $\mu$ s) of the voltage pulse at $63 \%$ of peak voltage, and $A$ is the electrode area (in $\mathrm{cm}^{2}$ ).
Equation (1) is based on measurements performed by Smith and colleagues and reported in Refs. [24-26,31], and an additional measurement by Shipman [34] which is reported in [26]. These measurements were made at 7 different values of $A$, which range from 50 to $5520 \mathrm{~cm}^{2}$. For 6 of these, the peak voltage is $\leq 1.5 \mathrm{MV}$; for 3 of these, the voltage is $<0.5 \mathrm{MV}$.

Equation (1) is similar to uniform-field waterbreakdown relations developed by the Atomic Weapons Research Establishment (AWRE) at Aldermaston, England $[24,25,30,31]$. The AWRE relation that is presented in Refs. [30,31] can be expressed as follows:

$$
E_{p} \tau_{\mathrm{eff}}^{1 / 3} A^{1 / 10}=0.3
$$

Although Eqs. (1) and (2) have the same exponent for $\tau_{\text {eff }}$, the exponents of $A$ differ. Equation (2) is based on the same set of measurements as is Eq. (1), with the exception of the measurement by Shipman.

As is well known [31], Eqs. (1) and (2) must cease to be applicable at sufficiently large values of $A$. When $\tau_{\text {eff }}$ is held constant, these equations predict that as $A \rightarrow \infty$, the value of $E_{p}$ required for complete dielectric failure approaches 0 . Similarly when $E_{p}$ is held constant, Eqs. (1) and (2) predict that as $A \rightarrow \infty$, the time required to achieve dielectric failure approaches 0 .

Consequently, Eqs. (1) and (2) must cease to be applicable to the design of a pulsed-power accelerator when the area of its water-insulated system is sufficiently large. We consider here a possible example of such a situation. We estimate that a future 1000-TW accelerator might require 
that the total area of the accelerator's intermediate-store capacitors be on the order of $5 \times 10^{7} \mathrm{~cm}^{2}$ [23]. Assuming that the effective pulse width of the voltage across such capacitors were to be $0.5 \mu \mathrm{s}$, Eq. (1) predicts that the breakdown electric field would be $0.104 \mathrm{MV} / \mathrm{cm}$. If the capacitors were to be designed to have a $20 \%$ safety factor, this would require that the field be limited to $0.083 \mathrm{MV} / \mathrm{cm}$. Equation (2) predicts that breakdown would occur at $0.064 \mathrm{MV} / \mathrm{cm}$; applying a $20 \%$ safety factor would require that the field be limited to $0.051 \mathrm{MV} / \mathrm{cm}$.

To determine whether the peak field in such a system of capacitors would, in fact, need to be as low as suggested by either Eq. (1) or (2), we develop in this article a waterbreakdown relation that estimates, for a given pulse width, the minimum value of $E_{p}$ that would be required to complete a dielectric breakdown. Thus we adopt the approach described in [31]; i.e., we develop an empirical waterstreamer transit-time relation. The relation, which is developed in Sec. II, is based in part on ideas developed in Chapter 7c of Ref. [31], and uses data that became available after that chapter was written.

In Sec. III, we use Eq. (1) and the relation developed in Sec. II to develop a design criterion for large-area waterinsulated systems. As we show in Sec. III, the criterion suggests that the large-area water-insulated system considered above could be operated at a much higher electric field than predicted by either Eq. (1) or (2). We discuss limitations of the design criterion, and present suggestions for future work, in Sec. IV.

In Appendix A, we demonstrate how the scaling suggested by Eq. (1) might be obtained from more fundamental considerations. In Appendix B, we evaluate one of the assumptions made in Sec. II.

\section{WATER-BREAKDOWN RELATION FOR LARGE-AREA SYSTEMS}

In this section we develop a dielectric-breakdown relation for large-area water-insulated pulsed-power systems. We begin by making the following simplifying assumptions.

(i) We assume that the characteristic time delay $\tau_{\text {delay }}$ between the application of a voltage to a water-insulated anode-cathode gap, and the completion of dielectric failure of that gap (assuming such a failure can occur), can be approximated as follows:

$$
\tau_{\text {delay }}=\tau_{\text {stat }}+\tau_{\text {form }}
$$

In this expression $\tau_{\text {stat }}$ is the statistical component of the delay time; i.e., the characteristic time between the application of the voltage and the appearance of the free electrons and ions that initiate the formation of streamers in the water. We define $\tau_{\text {form }}$ to be the formative component: the time required for the streamers to propagate across the gap and evolve sufficiently to produce complete dielectric failure.

Equation (3) is commonly assumed for modeling pulsed electrical breakdown of gas-filled spark gaps [35-40]; it is also assumed for millisecond-pulse water breakdown $[28,29]$ and vacuum-insulator flashover [41].

(ii) We assume that the area of a water-insulated system of interest is sufficiently large that the appearance of free electrons and ions necessary to initiate a breakdown occurs somewhere in the system very early in the voltage pulse. Under this condition, the statistical time delay $\tau_{\text {stat }}$ can be neglected, and the breakdown time delay is dominated by its formative component:

$$
\tau_{\text {delay }} \sim \tau_{\text {form}} .
$$

(iii) We assume that breakdown dominated by the formative component can be studied experimentally with a point-plane electrode geometry [31].

(iv) We assume that when the point in a point-plane geometry is the anode, $\tau_{\text {form }}$ is less than it is when the point is the cathode. This assumption is motivated by measurements performed by VanDevender and Martin [27] and Woodworth and colleagues [42], who observe that streamers that initiate from the positive electrode travel significantly faster than negative streamers. Hence we limit the analysis in this article to point-plane measurements made with a positive enhancement.

(v) We assume that voltage pulses of interest have normalized time histories that, to a reasonable approximation, are mathematically similar. We also assume that the water is homogeneous and isotropic, and has similar dielectric properties for all systems of interest. In addition, we assume that statistical fluctuations in the formative time can be neglected. Under these conditions, positive-enhanced point-plane breakdown in water is described by at most three independent variables. We can choose these to be $\tau_{\text {form }}, E_{p}$, and $d$.

\{When $\tau_{\text {delay }}$ is dominated by its statistical component, i.e., when $\tau_{\text {stat }} \gg \tau_{\text {form }}$ and $\tau_{\text {delay }} \sim \tau_{\text {stat }}$, then as shown in Refs. [29,41], the resulting water-breakdown relation, when expressed in a form similar to that given by Eq. (1), has identical exponents for the variables $\tau_{\mathrm{eff}}$ and $A$. Since the time exponent of Eq. (1) is much larger than the area exponent, this suggests that for the parameter regime over which Eq. (1) is valid, $\tau_{\text {form }}$ can no longer be neglected. We elaborate on this point in Appendix A. As discussed in the last paragraph of Sec. II A 1 of Ref. [41], when the formative component dominates, i.e., when $\tau_{\text {stat }} \ll \tau_{\text {form }}$ and $\tau_{\text {delay }} \sim \tau_{\text {form }}$, the resulting waterbreakdown relation is, under a certain set of conditions, independent of $A$. This is the parameter regime we consider in this article; i.e., we assume that the water-streamer transit-time relation is independent of $A$.\}

(vi) We assume that the dependence of the waterstreamer relation on $d$ is weak and can be neglected; i.e., 
we assume the relation depends only on $\tau_{\text {form }}$ and $E_{p}$. This assumption is also made by VanDevender and Martin in Ref. [27]. We evaluate this assumption in Appendix B.

When the above assumptions are valid, the peak field $E_{p}$ required to achieve complete dielectric failure is a function only of the time over which the voltage pulse is applied to the gap. The effective width of the voltage pulse $\tau_{\text {eff }}$ in water-breakdown studies is usually quoted as the width at $63 \%$ of peak voltage [24-27,30,31,43-49]; we adopt this convention herein to be consistent with the previous work. When voltage pulses of interest have normalized time histories that are mathematically similar (as assumed above), then $\tau_{\text {eff }} \propto \tau_{\text {delay }} \sim \tau_{\text {form. }}$.

Measurements performed with an ideal point-plane geometry, i.e., between an infinitely field-enhanced anode point and a flat cathode with infinite extent, are of course not possible. However, a number of measurements between a significantly enhanced anode electrode and a lessenhanced cathode have been described in the literature [27,42-46,50]; these are summarized in Table I.

Assuming that for these experiments the normalized shapes of the voltage pulses are sufficiently similar, we plot $E_{p}$ as a function of $\tau_{\text {eff }}$ in Fig. 1. Assuming $E_{p}$ is a power-law function of $\tau_{\text {eff }}$, we obtain from a regression analysis the following relation:

$$
E_{p} \tau_{\mathrm{eff}}^{0.330 \pm 0.026}=0.135 \pm 0.009 .
$$

This relation is plotted in Fig. 1.

The uncertainties given in Eq. (5) are $1 \sigma$ values. Hence the $\tau_{\text {eff }}$ exponent of Eq. (5) is within $3 \sigma$ of the exponent of the preliminary relation developed by VanDevender and Martin [27] for positive-streamer breakdown; this relation can be expressed as

$$
E_{p} \tau_{\text {eff }}^{0.4}=0.11
$$

Sandia National Laboratories has successfully used Eq. (6) for the design of several of its accelerators, including PROTO II, PBFA I, and PBFA II.

Since 1977, the pulsed-power community has also used J.C. Martin's preliminary relation for positive-streamer breakdown [31]:

$$
E_{p} \tau_{\text {eff }}^{0.5}=0.1
$$

This relation is often used even though Martin warned of the lack of data supporting Eq. (7) for voltages $>1 \mathrm{MV}$

TABLE I. Conditions under which complete dielectric breakdown of water is observed to occur. Each of these measurements was obtained with a significantly field-enhanced anode and a less-enhanced cathode, as described in Refs. [27,42-46,50]. The quantity $V_{p}$

\begin{tabular}{|c|c|c|c|c|c|}
\hline Reference & $\begin{array}{c}V_{p} \\
(\mathrm{MV})\end{array}$ & $\begin{array}{c}d \\
(\mathrm{~cm}) \\
\end{array}$ & $\begin{array}{c}E_{p} \\
(\mathrm{MV} / \mathrm{cm}) \\
\end{array}$ & $\begin{array}{l}\tau_{\text {eff }} \\
(\mu \mathrm{s})\end{array}$ & $E_{p} \tau_{\text {eff }}^{0.330}$ \\
\hline Corley and colleagues [44] & 1.94 & 5.72 & 0.339 & 0.063 & 0.136 \\
\hline Corley and colleagues [44] & 2.15 & 5.84 & 0.368 & 0.063 & 0.148 \\
\hline Corley and colleagues [44] & 2.34 & 7.11 & 0.329 & 0.070 & 0.137 \\
\hline Corley and colleagues [44] & 2.56 & 7.43 & 0.345 & 0.063 & 0.138 \\
\hline Puetz and colleagues $[45,46]$ & 2.07 & 7.63 & 0.271 & 0.077 & 0.116 \\
\hline Puetz and colleagues $[45,46]$ & 2.15 & 6.35 & 0.339 & 0.073 & 0.143 \\
\hline Puetz and colleagues $[45,46]$ & 2.32 & 7.63 & 0.304 & 0.094 & 0.139 \\
\hline Sazama and Kenyon [50] & 4.0 & 22 & 0.182 & 0.6 & 0.154 \\
\hline VanDevender [43] & 1.2 & 5.1 & 0.235 & 0.150 & 0.126 \\
\hline VanDevender [43] & 1.4 & 5.1 & 0.275 & 0.130 & 0.140 \\
\hline VanDevender [43] & 1.4 & 7.6 & 0.184 & 0.220 & 0.112 \\
\hline VanDevender [43] & 1.7 & 7.6 & 0.224 & 0.190 & 0.129 \\
\hline VanDevender [43] & 1.8 & 7.6 & 0.237 & 0.150 & 0.127 \\
\hline VanDevender [43] & 1.2 & 5.1 & 0.235 & 0.240 & 0.147 \\
\hline VanDevender [43] & 1.4 & 2.9 & 0.483 & 0.040 & 0.167 \\
\hline VanDevender [43] & 1.5 & 3.2 & 0.469 & 0.043 & 0.166 \\
\hline VanDevender and Martin [27] & & & 0.205 & 0.198 & 0.120 \\
\hline VanDevender and Martin [27] & & & 0.228 & 0.157 & 0.124 \\
\hline VanDevender and Martin [27] & For the & For the & 0.280 & 0.089 & 0.126 \\
\hline VanDevender and Martin [27] & measurements & measurements & 0.295 & 0.113 & 0.144 \\
\hline VanDevender and Martin [27] & described in & described in & 0.390 & 0.020 & 0.107 \\
\hline VanDevender and Martin [27] & $\begin{array}{l}\text { Ref. [27], } \\
\text { ( }\end{array}$ & Ref. [27], & 0.412 & 0.028 & 0.127 \\
\hline VanDevender and Martin [27] & $1 \leq V_{p} \leq 3 \mathrm{MV}$ & $1.25 \leq d \leq 5.7 \mathrm{~cm}$ & 0.463 & 0.015 & 0.116 \\
\hline VanDevender and Martin [27] & & & 0.695 & 0.011 & 0.155 \\
\hline Woodworth and colleagues [42] & 4.10 & 15 & 0.273 & 0.136 & 0.142 \\
\hline
\end{tabular}
is the peak voltage in time across the anode-cathode gap, $d$ is the length of the gap, $E_{p} \equiv V_{p} / d$, and $\tau_{\text {eff }}$ is the temporal width of the voltage pulse at $63 \%$ of peak. The last column assumes $E_{p}$ is expressed in $\mathrm{MV} / \mathrm{cm}$, and $\tau_{\text {eff }}$ in $\mu$ s. 


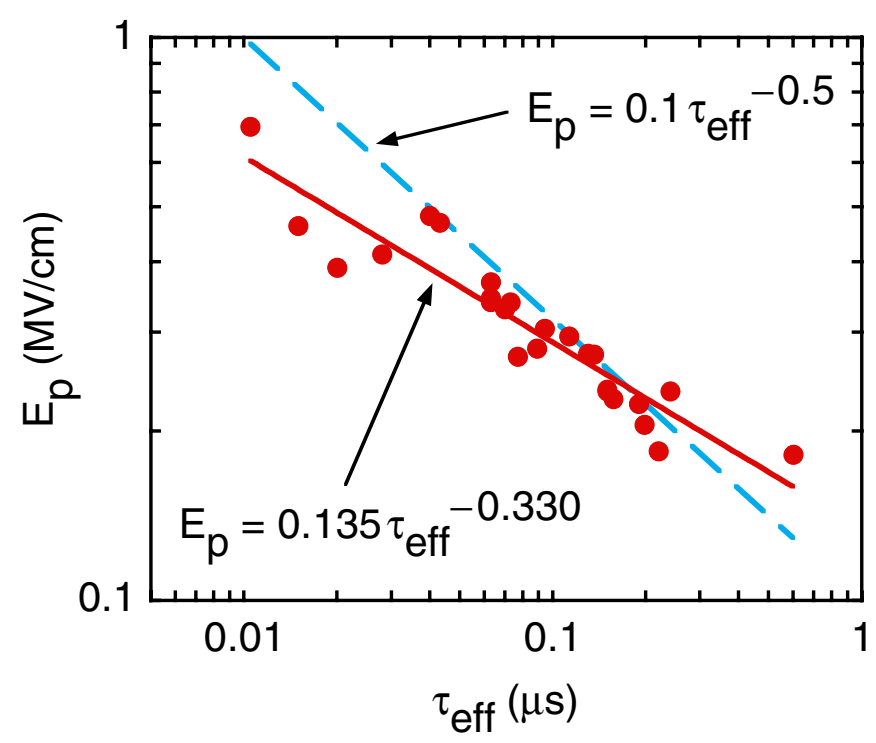

FIG. 1. (Color) The peak electric field required to achieve complete dielectric failure $E_{p}$ as a function of the effective pulse width $\tau_{\text {eff }}$. Each of the 25 measurements plotted here was obtained with a significantly field-enhanced anode and a lessenhanced cathode, as described in Refs. [27,42-46,50]. This data is summarized in Table I. We define $E_{p}$ as $V_{p} / d$, where $V_{p}$ is the peak voltage in time across the anode-cathode gap, and $d$ is the length of the gap. We define $\tau_{\text {eff }}$ to be the width of the voltage pulse at $63 \%$ of peak. It appears that the data are more consistent with Eq. (5) than Eq. (7).

[30,31]. This relation is also plotted in Fig. 1. As suggested by the figure, Eq. (5) is more consistent with experiment than is Eq. (7).

Equation (7) can be obtained from Fig. 7c-1 of Ref. [31]. However, according to this figure, when $V_{p}>1 \mathrm{MV}$, positive and negative streamers have the same average velocity, which is not consistent with the measurements reported in Refs. [27,42]. We also note that Chapter 7c of Ref. [31] proposes a refinement of Eq. (7):

TABLE II. For each of the water-breakdown relations given as Eqs. (5)-(8), we present here the normalized standard deviation $\sigma_{n}$ of the differences between the measurements listed in Table I and the associated predictions of the relation. For the first relation, we define $\sigma_{n}$ as indicated by Eq. (9). We define $\sigma_{n}$ for each of the other relations in a similar manner.

\begin{tabular}{lc}
\hline \hline $\begin{array}{c}\text { Water-breakdown } \\
\text { relation }\end{array}$ & $\begin{array}{c}\text { Normalized standard deviation } \sigma_{n} \text { of } \\
\text { the differences between the } \\
\text { measurements presented in Table I } \\
\text { and the predictions of each relation }\end{array}$ \\
\hline$E_{p} \tau_{\text {eff }}^{0.330}=0.135$ & $12 \%$ \\
$E_{p} \tau_{\text {eff }}^{0.4}=0.11$ & $14 \%$ \\
$E_{p} \tau_{\text {eff }}^{0.5}=0.1$ & $20 \%$ \\
$E_{p} \tau_{\text {eff }}^{0.5}=0.133$ & $36 \%$ \\
\hline \hline
\end{tabular}

$$
E_{p} \tau_{\mathrm{eff}}^{0.5}=0.133
$$

This expression is less consistent with the data in Table I than is Eq. (7).

In Table II we present, for each of the relations given by Eqs. (5)-(8), the normalized standard deviation of the differences between the data in Table I and the associated predictions of the relation. We define the normalized standard deviation $\sigma_{n}$ for the first relation [Eq. (5)] as follows:

$$
\sigma_{n}=\left[\frac{1}{25-1} \sum\left(\frac{E_{p} \tau_{\mathrm{eff}}^{0.330}-0.135}{0.135}\right)^{2}\right]^{1 / 2},
$$

where the sum is over the 25 measurements listed in Table I. The normalized standard deviation for each of the other three relations is similarly defined.

\section{DESIGN CRITERION FOR LARGE-AREA SYSTEMS}

Comparing Eqs. (1) and (5), and assuming that the $\tau_{\text {eff }}$ exponents of these two relations are essentially the same, we find that Eq. (5) should be used instead of Eq. (1) whenever

$$
A \geq 10^{4} \mathrm{~cm}^{2} .
$$

As noted previously, the largest area of the data used by Eilbert and Lupton to develop Eq. (1) is $5520 \mathrm{~cm}^{2}$ [2426,31,34].

However, we caution that Eq. (10) may not be entirely meaningful. The water-streamer relation given in Chapter 7c of Ref. [31] for voltages $<0.5 \mathrm{MV}$ differs significantly from the relation given for voltages $>1 \mathrm{MV}$, which suggests that water breakdown exhibits different behavior in these two voltage regimes. Equation (5) is based on voltages between 1 and $4.10 \mathrm{MV}$; however, much of the data used to develop Eq. (1) is less than $0.5 \mathrm{MV}$ [24-26,31], so it is uncertain whether Eqs. (1) and (5) can be combined to obtain Eq. (10).

In the absence of additional measurements, we make the tentative assumption that Eqs. (1) and (5) are both valid for voltages in excess of $1 \mathrm{MV}$. Assuming also that a $20 \%$ safety factor should be applied to Eq. (5) when used to design a system with $A \geq 10^{4} \mathrm{~cm}^{2}$, we obtain the following design criterion:

$$
E_{p} \tau_{\mathrm{eff}}^{0.330} \leq 0.108 \quad \text { when } A \gtrsim 10^{4} \mathrm{~cm}^{2} .
$$

Equation (11) is consistent with measurements conducted by Maxwell Labs on the transfer capacitor of the BLACKJACK-3 pulse generator, which demonstrate that breakdown does not occur in a water-insulated system when $\quad E_{p} \tau_{\mathrm{eff}}^{0.330}=0.119$ and $A=5.5 \times 10^{4} \mathrm{~cm}^{2}$ [31,47]. Equation (11) is also consistent with indirect measurements (i.e., direct measurements supplemented with circuit modeling) conducted on the $\mathrm{Z}$ accelerator [48], which show that breakdown does not occur when 
TABLE III. Conditions under which dielectric breakdown of water is observed not to occur. Each of these two observations was made on a large-area $\left(A \geqslant 10^{4} \mathrm{~cm}^{2}\right.$ ) water-insulated system with a nominally uniform electric field. The quantity $V_{p}$ is the peak voltage in time across the anode-cathode gap, $d$ is the length of the gap, $E_{p} \equiv V_{p} / d$, and $\tau_{\text {eff }}$ is the temporal width of the voltage pulse at $63 \%$ of peak. The last column assumes $E_{p}$ is expressed in $\mathrm{MV} / \mathrm{cm}$, and $\tau_{\text {eff }}$ in $\mu \mathrm{s}$. (The Maxwell-Lab data was taken on a transfer capacitor, with coaxial electrodes that have an outer radius of $60 \mathrm{~cm}$ and an inner radius of $48 \mathrm{~cm}$ [47]. The peak field $E_{p}$ given here for this data is that at the outer conductor, which is the anode, and has been corrected for the coaxial geometry.) The observations summarized here are consistent with the design criterion given by Eq. (11).

\begin{tabular}{|c|c|c|c|c|c|c|}
\hline Reference & $\begin{array}{c}A \\
\left(\mathrm{~cm}^{2}\right) \\
\end{array}$ & $\begin{array}{c}V_{p} \\
(\mathrm{MV})\end{array}$ & $\begin{array}{c}d \\
(\mathrm{~cm})\end{array}$ & $\begin{array}{c}E_{p} \\
(\mathrm{MV} / \mathrm{cm})\end{array}$ & $\begin{array}{c}\tau_{\text {eff }} \\
(\mu \mathrm{s})\end{array}$ & $E_{p} \tau_{\text {eff }}^{0.330}$ \\
\hline Measurements conducted by Maxwell Labs $[31,47]$ & $5.5 \times 10^{4}$ & 2.1 & 12 & 0.150 & 0.5 & 0.119 \\
\hline Stygar and colleagues [48] & $5.3 \times 10^{5}$ & 3.6 & 14 & 0.257 & 0.083 & 0.113 \\
\hline
\end{tabular}

$E_{p} \tau_{\mathrm{eff}}^{0.330}=0.113$ and $A=5.3 \times 10^{5} \mathrm{~cm}^{2}$. These largearea observations are summarized in Table III.

Presently, effective pulse widths for water-insulated systems of most interest range between $\sim 0.05$ and $\sim 1 \mu \mathrm{s}$. Hence, it is unfortunate that the literature only describes one point-plane measurement with $\tau_{\text {eff }}>0.3 \mu \mathrm{s}$, as indicated by Table I and Fig. 1. However, Table III suggests Eq. (5) is reasonably accurate when $\tau_{\text {eff }}=0.5 \mu \mathrm{s}$. According to assumption (ii) of Sec. II, and also Eq. (11), dielectric breakdown of a sufficiently large area follows the same relation as a point-plane system. If assumption (ii) and Eq. (11) are in fact valid, the BLACKJACK-3 data given in Table III suggests that when $\tau_{\text {eff }}=0.5 \mu \mathrm{s}$, point-plane breakdown occurs when $E_{p} \tau_{\text {eff }}^{0.330}>0.119$, which is consistent with Eq. (5). We note that this data is less consistent with Eq. (7), which predicts that the BLACKJACK-3 transfer capacitor should fail at a field that is $6 \%$ below the capacitor's normal operating field of $0.150 \mathrm{MV} / \mathrm{cm}[31,47]$.

An additional measurement with $\tau_{\text {eff }}>0.3 \mu \mathrm{s}$ is presented in Table 7c-II of Ref. [31]. This measurement was performed at $A=3000 \mathrm{~cm}^{2}$ and $\tau_{\text {eff }}=0.75 \mu \mathrm{s}$. Under these conditions, breakdown was observed to occur when $E_{p}=0.160 \mathrm{MV} / \mathrm{cm}$. (The peak voltage was on the order of 1.85 MV [31].) Since the area of this measurement is less than $10^{4} \mathrm{~cm}^{2}$, we use Eq. (1) to estimate that had this measurement been made at $10^{4} \mathrm{~cm}^{2}$, the peak electric field $E_{p}$ at breakdown would have been $0.149 \mathrm{MV} / \mathrm{cm}$. Hence, this suggests that when $\tau_{\text {eff }}=0.75 \mu \mathrm{s}$, point-plane breakdown occurs when $E_{p} \tau_{\text {eff }}^{0.330}=0.136$, in reasonable agreement with Eq. (5). This measurement is less consistent with Eq. (7), which predicts that under these conditions, the breakdown field $E_{p}$ would be $0.115 \mathrm{MV} / \mathrm{cm}$.

We revisit here the water-insulated system (with $A=$ $5 \times 10^{7} \mathrm{~cm}^{2}$ ) considered in Sec. I. According to Eq. (11), when $\tau_{\text {eff }}=0.5 \mu \mathrm{s}$, the peak electric field of such a system should be limited to $0.136 \mathrm{MV} / \mathrm{cm}$. This is $64 \%$ higher than the $0.083 \mathrm{MV} / \mathrm{cm}$ limit suggested by Eq. (1), and $164 \%$ higher than the $0.051 \mathrm{MV} / \mathrm{cm}$ limit suggested by Eq. (2), assuming $20 \%$ safety factors are applied to both Eqs. (1) and (2). [As discussed above, a 20\% safety factor is applied to Eq. (5) to arrive at Eq. (11).] Consequently, if Eq. (11) is valid, large-area water-insulated systems of interest can be operated at significantly higher electric fields than suggested by either Eq. (1) or (2).

\section{DISCUSSION}

\section{A. Limitations of the design criterion}

Equation (5) can be rewritten as

$$
\frac{V_{p}}{0.135 \tau_{\text {eff }}^{0.670}}=\frac{d}{\tau_{\text {eff }}} \equiv v_{\text {ave }},
$$

where $v_{\text {ave }}$ is the average streamer velocity across the anode-cathode gap. Assuming streamer propagation is driven by the electric field at the streamer tips, and that for frequencies of interest the dielectric constant of water is 80, then Eq. (5) [and hence Eq. (11)] are meaningful only when

$$
\frac{V_{p}}{0.135 \tau_{\mathrm{eff}}^{0.670}}<\frac{c}{\sqrt{80}}=3354 \mathrm{~cm} / \mu \mathrm{s},
$$

where $c$ is the speed of light in vacuum.

When Eq. (13) is not valid, the design criterion given by Eq. (11) should be replaced by one of the following form:

$$
k \frac{d}{\tau_{\text {eff }}}>3354 \mathrm{~cm} / \mu \mathrm{s},
$$

where $k$ is a suitably defined constant. This constant would be defined so that Eq. (14) guarantees that streamers cannot physically cross the gap during the duration of the voltage pulse. The velocity on the right-hand-side of Eq. (14) is $0.11 c$; we note that peak (i.e., not average) water-streamerpropagation velocities as high as $0.01 c$ have been observed by Woodworth and colleagues [42].

Even when Eq. (13) is valid, we caution that Eq. (11) is only applicable for the first pulse applied to a waterinsulated system during an accelerator shot, since Eq. (11) does not account for effects due to subsequent pulses (such as might be caused by reflections) on a system's dielectric strength. We also caution that Eq. (11) is not necessarily 
applicable at an interface between water and a solid insulator.

\section{B. Suggestions for future work}

For the measurements listed in Table I, $1 \leq V_{p} \leq$ $4.10 \mathrm{MV}, 1.25 \leq d \leq 22 \mathrm{~cm}$, and $0.011 \leq \tau_{\text {eff }} \leq 0.6 \mu \mathrm{s}$. However, these measurements do not include all physically reasonable combinations of the variables $V_{p}, d$, and $\tau_{\text {eff }}$ within these ranges, but only a small subset. In addition, it is not clear how far Eq. (11) can be extrapolated beyond these ranges. Hence Eq. (11) is being proposed here only as a tentative design criterion; we suggest that additional experiments be conducted over a wider parameter regime to develop a definitive criterion. Such experiments would be similar to those described in Refs. [27,31,42-46,49,50].

Additional experiments performed with relatively uniform electric fields and large areas, such as the experiments described in Refs. [24,25,28,29,31-34,47,48], would also be of interest, to determine whether Eq. (11) is, in fact, a reasonable criterion.

In addition, we note that Eq. (11) is valid only when the shape of the voltage pulse in question is, to a reasonable approximation, mathematically similar to those used for the measurements presented in Table I. To generalize Eq. (11) for use with arbitrary pulse shapes, we propose that a relation of the following form be developed $[41,49]$ :

$$
\int_{0}^{\tau} E^{\alpha}(t) d t=\gamma
$$

where $\tau$ is the full width of the voltage pulse at its base, and $\alpha$ and $\gamma$ are constants.

\section{ACKNOWLEDGMENTS}

The authors would very much like to acknowledge R. Anderson, J. Boyes, P. Corcoran, T. Cutler, D. Dalton, J. Douglas, S. Drennan, D. Fehl, T. Gilliland, D. Guthrie, K. Hodge, M. Horry, T. Jaramillo, D. L. Johnson, M. Johnson, R. Leeper, F. Long, J. Maenchen, T. Martin, M. K. Matzen, D. McDaniel, O. Milton, M. Mostrom, D. Muirhead, T. Mulville, J. Porter, J. Ramirez, L. Ramirez, P. Reynolds, T. Romero, J. Seamen, R. W. Shoup, I. D. Smith, J. Smith, C.S. Speas, R. Spielman, K. Struve, G. Vogtlin, D. Wetz, O. Yamamoto, and F. Zutavern for critical contributions, and T. Cutler for graciously reviewing this article. In addition, we very much wish to thank our many other colleagues at Sandia National Laboratories, Ktech Corporation, Team Specialty Products, C-Lec Plastics, EG\&G, Lawrence Livermore National Laboratory, Mission Research Corporation, Prodyn Technologies, Titan-Pulse Sciences Division, U. of Texas, Voss Scientific, and Votaw Precision Technologies for supporting this work. Sandia is a multiprogram laboratory operated by Sandia Corporation, a Lockheed Martin Company, for the United States
Department of Energy's National Nuclear Security Administration under Contract No. DE-AC04-94AL85000.

\section{APPENDIX A: DEVELOPING A DIELECTRIC- BREAKDOWN RELATION FROM EXPRESSIONS FOR $\tau_{\text {stat }}$ AND $\tau_{\text {form }}$}

In this appendix we discuss how a dielectric-breakdown relation of the form given by Eq. (1) can be obtained from expressions for $\tau_{\text {stat }}$ and $\tau_{\text {form }}$.

According to Refs. [28,29,41], when the dielectricbreakdown time delay $\tau_{\text {delay }}$ of a system is dominated by $\tau_{\text {stat }}$, the exponents of $\tau_{\text {eff }}$ and $A$ in the corresponding breakdown relation, when expressed in the form given by Eq. (1), are identical. (This statement assumes that the relevant size variable of the system in question is the area $A$. For vacuum-insulator flashover, the relevant size variable is $C$, the insulator circumference [41].)

For water breakdown dominated by $\tau_{\text {stat }}$, under the conditions studied in Ref. [28], it appears that

$$
\tau_{\text {stat }}=\frac{\gamma_{1}}{E_{p}^{12.5} A}
$$

where $\gamma_{1}$ is a constant. For water breakdown dominated by $\tau_{\text {form }}$, under the conditions studied in Sec. II of the present article, we find that

$$
\tau_{\text {form }}=\frac{\gamma_{2}}{E_{p}^{3.03}}
$$

where $\gamma_{2}$ is a constant.

Combining Eqs. (3), (A1), and (A2), and assuming that the shapes of the voltage pulses for systems of interest are mathematically similar (so that when breakdown occurs, $\tau_{\text {eff }} \propto \tau_{\text {delay }}$ ), we find that in general

$$
\tau_{\mathrm{eff}} \propto \frac{\gamma_{1}}{E_{p}^{12.5} A}+\frac{\gamma_{2}}{E_{p}^{3.03}}
$$

Hence,

$$
\frac{E_{p}^{12.5} \tau_{\mathrm{eff}} A}{1+\gamma_{3} E_{p}^{9.47} A}=\gamma_{4}
$$

where $\gamma_{3}$ and $\gamma_{4}$ are constants. Making the following approximation,

$$
\left(1+\gamma_{3} E_{p}^{9.47} A\right) \propto\left(E_{p}^{9.47} A\right)^{\beta},
$$

where

$$
0 \leq \beta \leq 1,
$$

we find that 


$$
E_{p} \tau_{\text {eff }}^{1 /(12.5-9.47 \beta)} A^{(1-\beta) /(12.5-9.47 \beta)}=\gamma_{5}
$$

where $\gamma_{5}$ is a constant.

The case $\beta=0$ corresponds to when $\tau_{\text {stat }}$ dominates; the case $\beta=1$ when $\tau_{\text {form }}$ dominates. When $\beta=0.95$ we obtain

$$
E_{p} \tau_{\mathrm{eff}}^{0.29} A^{0.014}=\gamma_{5}
$$

We have performed a multiple-regression analysis on the water-breakdown data presented in [24-26,31], and instead of Eq. (1), we obtain the following relation:

$$
E_{p} \tau_{\text {eff }}^{0.316 \pm 0.021} A^{0.057 \pm 0.019}=0.248 \pm 0.038 .
$$

The uncertainties presented in Eq. (A9) are $1 \sigma$ values. Hence, to within $\sim 2 \sigma$ (the usual standard for determining whether a discrepancy is significant [51]), Eqs. (A8) and (A9) are consistent. [However, we caution that such a comparison may not be meaningful. The data upon which Eq. (A1) is based was taken with voltages $<0.2 \mathrm{MV}$, and much of the data upon which Eq. (A9) is based was taken with voltages $<0.5 \mathrm{MV}$. The data upon which Eq. (A2) is based was taken with voltages between 1 and $4.10 \mathrm{MV}$. According to Chapter 7c of Ref. [31], the water-streamer relation for voltages $<0.5 \mathrm{MV}$ differs significantly from the relation obtained for voltages $>1 \mathrm{MV}$, which suggests that water breakdown exhibits different behavior in these two voltage regimes. Hence, it is not clear we can combine Eqs. (A1) and (A2) to obtain Eq. (A8), as described above, nor that we can compare Eq. (A8) to Eq. (A9).]

When neither $\tau_{\text {stat }}$ nor $\tau_{\text {form }}$ dominates, a dielectricbreakdown relation may be more accurately expressed in a form similar to that given by Eq. (A4) than Eq. (A8), since an equation such as Eq. (A4) more accurately accounts for contributions from both $\tau_{\text {stat }}$ and $\tau_{\text {form }}$ to the delay time $\tau_{\text {delay }}$.

\section{APPENDIX B: DEPENDENCE OF THE WATER- BREAKDOWN RELATION ON THE ANODE- CATHODE GAP $d$}

In Sec. II, we make the simplifying assumption that the water-streamer transit-time relation developed in this article is independent of the anode-cathode gap $d$. We evaluate this assumption below.

Table I lists 25 point-plane measurements; the gap $d$ is available for 17 of these. When we assume $E_{p}$ is a function of both $\tau_{\text {eff }}$ and $d$, and perform a multiple-regression analysis on these 17 measurements, we obtain instead of Eq. (5) the following relation:

$$
E_{p} \tau_{\text {eff }}^{0.360 \pm 0.053} d^{0.030 \pm 0.077}=0.137 \pm 0.038 .
$$

At the $95 \%$ confidence level, the exponent of $d$ is between -0.136 and 0.196 . Hence, we presently do not have sufficient evidence to determine whether the exponent of $d$ differs significantly from 0 . Consequently, it appears that, for the available data, we are justified in assuming that the dependence of the water-streamer transit-time relation on $d$ can be neglected. Of course, as more data become available, this assumption should be reexamined.

[1] R. B. Spielman, W. A. Stygar, J. F. Seamen, F. Long, H. Ives, R. Garcia, T. Wagoner, K.W. Struve, M. Mostrom, I. Smith, P. Spence, and P. Corcoran, in Proceedings of the 11th IEEE International Pulsed Power Conference, edited by G. Cooperstein and I. Vitkovitsky (IEEE, Piscataway, NJ, 1997), p. 709.

[2] P. A. Corcoran, J. W. Douglas, I. D. Smith, P. W. Spence, W. A. Stygar, K. W. Struve, T. H. Martin, R. B. Spielman, and H.C. Ives, in Proceedings of the 11th IEEE International Pulsed Power Conference (Ref. [1]), p. 466.

[3] R. J. Garcia, H. C. Ives, K. W. Struve, R. B. Spielman, T.H. Martin, M.L. Horry, R. Wavrik, and T.F. Jaramillo, in Proceedings of the 11th IEEE International Pulsed Power Conference (Ref. [1]), p. 1614.

[4] H. C. Ives, D. M. Van De Valde, F. W. Long, J. W. Smith, R. B. Spielman, W. A. Stygar, R. W. Wavrick, and R. W. Shoup, in Proceedings of the 11th IEEE International Pulsed Power Conference (Ref. [1]), p. 1602.

[5] M. A. Mostrom, T. P. Hughes, R. E. Clark, W. A. Stygar, and R.B. Spielman, in Proceedings of the 11th IEEE International Pulsed Power Conference (Ref. [1]), p. 460.

[6] R. W. Shoup, F. Long, T. H. Martin, R. B. Spielman, W. A. Stygar, M. A. Mostrom, K. W. Struve, H. Ives, P. Corcoran, and I. Smith, in Proceedings of the 11th IEEE International Pulsed Power Conference (Ref. [1]), p. 1608.

[7] I. D. Smith, P. A. Corcoran, W. A. Stygar, T. H. Martin, R. B. Spielman, and R. W. Shoup, in Proceedings of the 11th IEEE International Pulsed Power Conference (Ref. [1]), p. 168.

[8] K. W. Struve, T. H. Martin, R. B. Spielman, W. A. Stygar, P. A. Corcoran, and J. W. Douglas, in Proceedings of the 11th IEEE International Pulsed Power Conference (Ref. [1]), p. 162.

[9] W. A. Stygar, R. B. Spielman, G. O. Allshouse, C. Deeney, D. R. Humphreys, H. C. Ives, F. W. Long, T. H. Martin, M. K. Matzen, D. H. McDaniel, C. W. Mendel, Jr., L.P. Mix, T. J. Nash, J. W. Poukey, J. J. Ramirez, T. W. L. Sanford, J. F. Seamen, D. B. Seidel, J. W. Smith, D. M. Van De Valde, R. W. Wavrik, P. A. Corcoran, J.W. Douglas, I. D. Smith, M. A. Mostrom, K. W. Struve, T.P. Hughes, R. E. Clark, R. W. Shoup, T. C. Wagoner, T. L. Gilliland, and B. Peyton, in Proceedings of the 11th IEEE International Pulsed Power Conference (Ref. [1]), p. 591.

[10] R. B. Spielman, C. Deeney, G. A. Chandler, M. R. Douglas, D. L. Fehl, M. K. Matzen, D. H. McDaniel, T. J. Nash, J. L. Porter, T. W. L. Sanford, J. F. Seamen, W. A. Stygar, K. W. Struve, S. P. Breeze, J. S. McGurn, J. A. Torres, D. M. Zagar, T. L. Gilliland, D. O. Jobe, J. L. McKenney, R. C. Mock, M. Vargas, T. Wagoner, and D. L. Peterson, Phys. Plasmas 5, 2105 (1998).

[11] J.J. Ramirez, in Proceedings of the 10th IEEE International Pulsed Power Conference, edited by W. 
Baker and G. Cooperstein (IEEE, Piscataway, NJ, 1995), p. 91.

[12] T.H. Martin (unpublished).

[13] K. W. Struve and D. H. McDaniel, in Proceedings of the 12th International Conference on High-Power Particle Beams (Beams '98), edited by M. Markovits and J. Shiloh (IEEE, Haifa, Israel, 1998), p. 334.

[14] P. Sincerny, M. Danforth, C. Gilbert, A. R. Miller, T. Naff, W. Rix, C. Stallings, E. Waisman, and L. Schlitt, in Proceedings of the 12th IEEE International Pulsed Power Conference, edited by C. Stallings and H. Kirbie (IEEE, Piscataway, NJ, 1999), p. 479.

[15] K. W. Struve, J. P. Corley, D. L. Johnson, D. H. McDaniel, R. B. Spielman, and W. A. Stygar, in Proceedings of the 12th IEEE International Pulsed Power Conference (Ref. [14]), p. 493.

[16] P. Corcoran, I. Smith, P. Spence, A. R. Miller, E. Waisman, C. Gilbert, W. Rix, P. Sincerny, L. Schlitt, and D. Bell, in Proceedings of the 13th IEEE International Pulsed Power Conference, edited by R. Reinovsky and M. Newton (IEEE, Piscataway, NJ, 2001), p. 577.

[17] M. G. Mazarakis, R. B. Spielman, K. W. Struve, and F. W. Long, in Proceedings of the 13th IEEE International Pulsed Power Conference (Ref. [16]), p. 587.

[18] D. H. McDaniel, M. G. Mazarakis, D. E. Bliss, J. M. Elizondo, H.C. Harjes, H. C. Ives III, D. L. Kitterman, J. E. Maenchen, T.D. Pointon, S.E. Rosenthal, D. L. Smith, K. W. Struve, W. A. Stygar, E. A. Weinbrecht, D. L. Johnson, and J.P. Corley, in Dense Z Pinches: Proceedings of the 5th International Conference on Dense Z Pinches, edited by J. Davis, C. Deeney, and N. Pereira, AIP Conf. Proc. 651 (AIP, Melville, NY, 2002), p. 23.

[19] P. Spence, P. Corcoran, J. Douglas, T. Tucker, B. Altes, K. Childers, P. Sincerny, L. Whitehead, V. Kenyon, M. Babineau, T. Cotter, P. Kurucz, and R. Davis, in Dense $\mathrm{Z}$ Pinches: the Proceedings of the 5th International Conference on Dense Z Pinches (Ref. [18]), p. 43.

[20] M. G. Mazarakis, W.E. Fowler, F.W. Long, D. H. McDaniel, C. L. Olson, S. T. Rogowski, R. A. Sharpe, and K.W. Struve, in Proceedings of the 15th IEEE International Pulsed Power Conference (IEEE, Piscataway, NJ, to be published).

[21] C.L. Olson, in Landholt-Boernstein Handbook on Energy Technologies, Fusion Technologies, edited by K. Heinloth (Springer-Verlag, Berlin-Heidelberg, 2005), Vol. VIII/3.

[22] W. A. Stygar, M. E. Cuneo, R. A. Vesey, H. C. Ives, M. G. Mazarakis, G. A. Chandler, D. L. Fehl, R. J. Leeper, M. K. Matzen, D. H. McDaniel, J. S. McGurn, J. L. McKenney, D. J. Muron, C. L. Olson, J. L. Porter, J. J. Ramirez, J. F. Seamen, C. S. Speas, R. B. Spielman, K. W. Struve, J. A. Torres, E. M. Waisman, T. C. Wagoner, and T. L. Gilliland, Phys. Rev. E 72, 026404 (2005).

[23] W. A. Styar, M. E. Cuneo, D. I. Headley, H. C. Ives, R. J. Leeper, M. G. Mazarakis, C.L. Olson, J.L. Porter, and T. C. Wagoner (unpublished).

[24] I. D. Smith, Atomic Weapons Research Establishment Report No. SSWA/JCM/6511/B, 1965.

[25] I. D. Smith, Atomic Weapons Research Establishment Report No. SSWA/IDS/6610/100, 1966.
[26] R. A. Eilbert and W. H. Lupton (unpublished).

[27] J.P. VanDevender and T.H. Martin, IEEE Trans. Nucl. Sci. 22, No. 3, 979 (1975).

[28] F. Zutavern and M. Buttram, in 1983 Annual ReportConference on Electrical Insulation and Dielectric Phenomena (IEEE, Piscataway, NJ, 1983), p. 251.

[29] F. J. Zutavern, M. T. Buttram, and M. W. O'Malley, in IEEE Conference Record of 1984 Sixteenth Power Modulator Symposium, edited by K. Baile, S. Schneider, B. Gray, S. Levy, R. Pollard, and L. H. Klein (IEEE, Piscataway, NJ, 1984), p. 273.

[30] J. C. Martin, Proc. IEEE 80, 934 (1992).

[31] J.C. Martin, in J. C. Martin on Pulsed Power, edited by T. H. Martin, A. H. Guenther, and M. Kristiansen (Plenum, New York, 1996).

[32] D. A. Wetz, in Proceedings of the 15th IEEE International Pulsed Power Conference (IEEE, Piscataway, NJ, to be published).

[33] D. A. Wetz, IEEE Trans. Plasma Sci. (to be published).

[34] J.D. Shipman (unpublished).

[35] R. Strigel, Elektrotech. Z. 59, 33 (1938).

[36] J.M. Meek and J.D. Craggs, Electrical Breakdown of Gases (Clarendon, Oxford, 1953).

[37] J.D. Cobine, Gaseous Conductors (Dover, New York, 1958), pp. 186-193.

[38] F. Llewellyn-Jones, Ionization and Breakdown in Gases (Wiley, New York, 1966).

[39] Electrical Breakdown of Gases, edited by J. M. Meek and J. D. Craggs (Wiley, New York, 1978).

[40] Yu.D. Korolev, and G. A. Mesyats, Physics of Pulsed Breakdown in Gases (URO, Ekaterinburg, 1998).

[41] W. A. Stygar, H.C. Ives, T.C. Wagoner, J.A. Lott, V. Anaya, H. C. Harjes, J. P. Corley, R. W. Shoup, D. L. Fehl, G. R. Mowrer, Z. R. Wallace, R. A. Anderson, J. D. Boyes, J. W. Douglas, M. L. Horry, T. F. Jaramillo, D. L. Johnson, F. W. Long, T. H. Martin, D. H. McDaniel, O. Milton, M. A. Mostrom, D. A. Muirhead, T. D. Mulville, J. J. Ramirez, L. E. Ramirez, T. M. Romero, J. F. Seamen, J. W. Smith, C. S. Speas, R. B. Spielman, K. W. Struve, G. E. Vogtlin, D. E. Walsh, E. D. Walsh, M. D. Walsh, and O. Yamamoto, Phys. Rev. ST Accel. Beams 7, 070401 (2004).

[42] J. R. Woodworth, J. M. Lehr, J. Elizondo-Decanini, P. A. Miller, P. Wakeland, M. Kincy, J. Garde, B. Aragon, W. Fowler, G. Mowrer, J.E. Maenchen, G. S. Sarkisov, J. Corley, K. Hodge, S. Drennan, D. Guthrie, M. Navarro, D. L. Johnson, H. C. Ives, M. J. Slattery, and D. A. Muirhead, IEEE Trans. Plasma Sci. 32, 1778 (2004).

[43] J. P. VanDevender, J. Appl. Phys. 49, 2616 (1978).

[44] J. P. Corley, D. L. Johnson, G. J. Weber, G. J. Denison, P. J. Pankuch, and J.J. Ramirez, in Proceedings of the 6th IEEE International Pulsed Power Conference, edited by P. J. Turchi and B.H. Bernstein (IEEE, Piscataway, NJ, 1987), p. 486.

[45] E. Puetz, I. Molina, S. Portillo, S. Cordova, D. L. Johnson, and P. Corcoran, in Proceedings of the 14th IEEE International Pulsed Power Conference, edited by M. Giesselmann and A. Neuber (IEEE, Piscataway, NJ, 2004), p. 899.

[46] E. Puetz, I. Molina, S. Portillo, S. Cordova, D. L. Johnson, and P. Corcoran (unpublished). 
[47] A. R. Miller, in Proceedings of the 3rd IEEE International Pulsed Power Conference, edited by T.H. Martin and A. H. Guenther (IEEE, Piscataway, NJ, 1981), p. 200.

[48] W. A. Stygar, P. A. Corcoran, R. J. Garcia, H. C. Ives, T. H. Martin, R. W. Shoup, R. B. Spielman, K. W. Struve, and T. C. Wagoner (unpublished).

[49] K. A. Mikkelson, W.B. Moore, and J.P. VanDevender,
Sandia National Laboratories Report No. SAND83-1503, 1983.

[50] F. J. Sazama and V. L. Kenyon III, IEEE Trans. Plasma Sci. 8, No. 3, 198 (1980).

[51] J. R. Taylor, An Introduction to Error Analysis (University Science Books, Sausalito, California, 1997). 